\title{
CULTURAL ROUTES AS A SOURCE FOR NEW KIND OF TOURISM DEVELOPMENT: EVIDENCE FROM THE COUNCIL OF EUROPE'S PROGRAMME
}

\author{
Dr. K. M. Khovanova-Rubicondo, a \\ a Council of Europe Programme on Cultural Routes, Council of Europe, 1 Ave de l'Europe, Strasbourg 67000, France \\ kseniya.khovanova@culture-routes.lu
}

KEY WORDS: Cultural Routes, Sustainable Cultural Tourism, Network Governance, SMEs Generation, Innovation, TransNational networks, Cultural Tourism Products.

\begin{abstract}
:
Europe offers a wide variety of cultural itineraries that, crossing several regions or countries, provide a living example of the rich and impressive European common heritage. For more than two decades 24 of such itineraries have been jointly collaborating under the Council of Europe's (CoE) Cultural Routes Programme aimed at preserving the diversity of European culture and heritage, and to promote understanding of Europe's history. Today, when cultural heritage is more and more often viewed as a new form of good cultural good, - methods of heritage management are changing to incorporate new elements, which could help local communities to draw more obvious benefits from their cultural legacy while preserving and maintaining its uniqueness. Often these elements come from tourism: a new kind of tourism, which is respectful of the environment, of the natural and cultural heritage and of the local traditions. This article offers an overview of the Study on the CoE Cultural Routes Impact on Tourism SMEs (Khovanova et al., 2011) that demonstrated how the need for implementing sustainable tourism management practices is growing within the $\mathrm{CoE}$ cultural routes. One of the breaking findings of the Study was that, even though founded on social and cultural principles, CoE routes today serve as a source of innovation, small business creation, local income generation, and cultural tourism products development. These potentials are now been reinforced by building in sustainable tourism elements in cultural routes management practices, and by bringing the benefits of ICT and digitalization, following the Study recommendations. The findings of the Study could also help cultural heritage managers and policy makers around the globe to better understand tourism potential of cultural heritage sites, while encouraging respectful and sustainable management approaches.
\end{abstract}

\section{INTRODUCTION}

The Council of Europe's Cultural Routes Programme was established in 1987 aiming to preserve the diversity of European culture and heritage, to promote understanding of Europe's history on the basis of its physical, intangible, and natural heritage, and to improve public awareness about the unique in its diversity European history and culture.

As recognised by the Council of Europe (CoE), cultural route is a cultural project aimed at the development and promotion of an itinerary or network based on a historic route, a cultural concept, figure or phenomenon of a transnational importance that manifests common European values. Extending from the Atlantic to the Southern Caucasus and from the Baltic to the Mediterranean, $\mathrm{CoE}$ cultural routes enable improved understanding of the history and memory of Europe in a transcontinental dimension. CoE Cultural Routes Programme comprises 24 certified Routes that cover 70 countries in the world. Statistical analysis of the CoE cultural routes crossings in these countries demonstrated the density of the cultural route networks.

Graph 1 shows the percentage share of the routes' networks by country. France $(10.4 \%)$ is a leader in CoE cultural routes' networks accumulation followed by Italy $(9.7 \%)$, Spain $(8.4 \%)$, Portugal (5.8\%), Germany (5.2\%) and the Great Britain (5.2\%). The rest of the countries contain $2.6 \%$ or smaller percentage of cultural route networks density per country. These nations form three large groups that represent the unexploited potential for the CoE cultural routes development in the countries now not well represented, for the future.

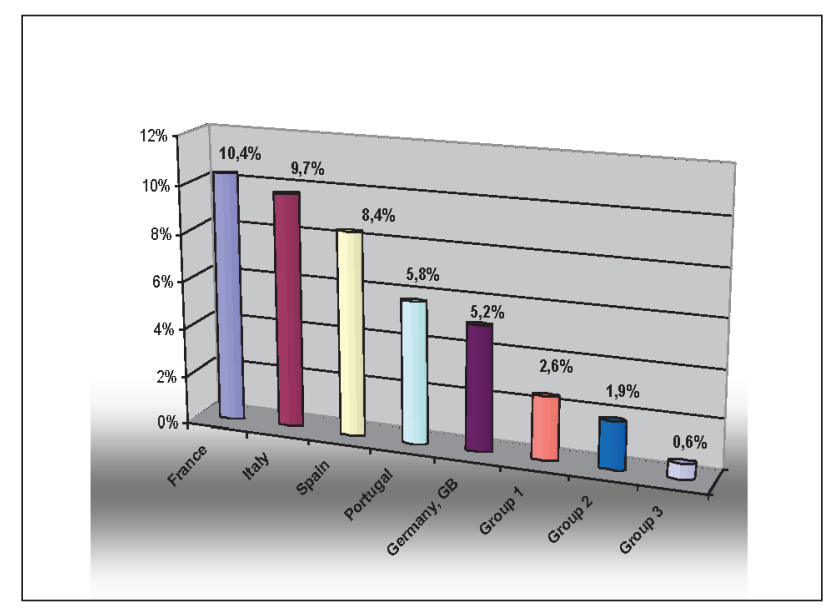

Graph 1. CoE cultural routes share per country

Group 1: Belgium, Czech Republic, Greece, Norway, Poland, Sweden, Switzerland

Group 2: Algeria, Austria, Croatia, Cyprus, Lebanon, Morocco, Netherlands, Slovenia, Tunisia

Group 3: Albania, Argentina, Armenia, Azerbaijan, Belarus, Bulgaria, Denmark, Estonia, Jordan, Lithuania, Malta, Romania, Russia, Serbia, Slovakia, Syria, Turkey, Ukraine 
While diverse in their cultural legacy, thematic focus, target groups, and network structures, the $\mathrm{CoE}$ cultural routes are united in their common goal to manage their cultural heritage professionally and sustainably, in a way to assure its continuous protection and preservation, and to draw obvious benefits from their cultural legacy for local communities along the routes' destinations.

It is this emphasis on sustainable and responsible heritage management - the focal point of which is social wellbeing and economic development of local communities, their environmental and natural resource protection, respect of sociocultural authenticity and diversity of their cultural legacy and traditions - that makes the CoE Cultural Routes Programme different from similar international initiatives run by UNESCO, UNWTO, the Organization of Ibero-American States, and others.

At the same time, our routes operate equally taking into account and promoting the charters, conventions, recommendations and work of the Council of Europe, UNESCO and ICOMOS relating to heritage restoration, protection and enhancement, landscape and spatial planning. Besides, the $\mathrm{CoE}$ Cultural Routes Programme works together with its international partners to develop a coherent roadmap for cooperation between the Council of Europe Cultural Routes and related UNESCO, UNWTO and other programs, especially those already associated with the $\mathrm{CoE}$ cultural routes. We aim to establish a competitive and effective joint strategy to preserve the diversity of European culture and heritage, and promote understanding of Europe's history.

\section{THE STUDY}

In 2011, the Council of Europe (CoE) launched a Study on the Impact of the European Cultural Routes (KhovanovaRubicondo et al., 2011) jointly funded by the European Commission (DG Enterprise \& Industry). The goals of the Study were largely predetermined by 'the need of the day' to better understand the reality and nowadays potential of $\mathrm{CoE}$ cultural routes following two decades of the Programme operation. These goals were also set in line with the vision of the Europe 2020 strategy, which focuses on policies to create smart, sustainable and inclusive growth, to promote economic, social and territorial cohesion in Europe, taking into account that culture-based activities such as cultural routes projects are capable of making significant contributions to local economies and the prosperity of Europe in general.

More precisely, the Study thus aimed to provide insights on the effects produced by the CoE Cultural Routes Programme on local economies in terms of SMEs generation, their performance, network and cluster development; to examine the potential of the Cultural Routes for promoting cultural tourism in Europe; and to analyze how much $\mathrm{CoE}$ cultural route networks can benefit local communities, especially in lessknown destinations, via SMEs creation. The main expectations from the Study were thus to:

identify key actors involved today in the cultural routes (SMEs, NGOs, associations),

understand the challenges and advantages of cultural routes' environments (especially in the context of the current economic conditions), and
- $\quad$ estimate cultural routes potentials, their needs and concerns on the way to sustainable cultural tourism development.

\section{Methodology}

The CoE team worked closely with the main Study stakeholders, group of independent experts, and cultural routes coordinators to design an appropriate analytical framework. At the outset, the study team set up an advisory group with key partners including representatives from the EC (DG Enterprise and Industry, DG Education and Culture), the European Travel Commission, and the European Institute of Cultural Routes (EICR). Considering the complexity and novelty of the field, a consultative group of experts was invited from academia and practice to ensure the input of a range of disciplines, professional backgrounds, and partner organizations, and to guarantee a sound methodology. Key steps of the Study included:

- Identification of experts

- Cultural routes Survey

- Creation of cultural routes analytical grid

- Case studies of 5 selected cultural routes

- Intermediary Study results

- Transversal themes and issues analysis

- Final conclusions and recommendations

The Study included two main phases that followed a CoEadministered survey of $29 \mathrm{CoE}$-certified cultural routes. This exercise was important not only in terms of current qualitative and quantitative data and information gathering for the selection of case studies but also in a way to assess the overall potential of CoE Cultural Routes Programme development.

The methodology of Phase I was based on a set of case studies of five representatively selected cultural routes - the Hansa, the Legacy of Al-Andalus, the Via Francigena, the Olive Tree, and the Transromanica. A cultural routes' classification grid was created based on the information obtained from the CoE survey and included the following categories:

- Cultural route focus and geographical area

- Type of managing organization (legal entity)

- Number of SMEs and NPOs involved

- New products/posts created

- Sources of financing

- Cultural route network connectivity

- Spatial accumulation

- $\quad$ Existing marketing tools

- Target audience.

The cultural route case studies were selected in close consultation with the Study expert group. Each of these studies followed an individual methodological approach most appropriate to its case, designed by the expert working on the study. The goal was to capture in depth as much data as possible from the locations within the cultural route networks. Generally, the methodology of the case studies included the following elements:

a review of relevant literature and documents concerning the routes,

desk research: review of the related material and information available online including cultural routes' web pages, open source information, 
- meetings and interviews with the key stakeholders of the route that provided a useful overview of the management, key activities, and future plans, a survey of cultural route locations-members of the network, and

data analysis and presentation.

Phase I was completed in March 2011. Its main conclusions and recommendations were presented at the "Innovation and competitiveness within the European Cultural Routes projects: analysis, opinions and perspectives" Workshop in Luxembourg on 28-29 March 2011.

Phase II of the Study focused on the transversal issues relevant to all $29 \mathrm{CoE}$-certified cultural routes and to the environments in which they were operating. In particular, these issues included:

- $\quad$ cultural tourism trends in Europe ;

cultural routes' management and governance structures ;

SMEs innovation and competitiveness ;

branding and marketing of the cultural routes; characteristics of the cultural routes' networks; the role of ICT in cultural routes marketing and promotion;

- CoE Cultural Routes Programme in the context of relevant initiatives at European and international levels;

Within this phase a number of interviews were conducted by the Council of Europe with international level organizations such as UNESCO and the Organization of Ibero-American States inquiring about the current stage of development and future implementation strategies of the related cultural initiatives coordinated by these organizations in Eastern Europe, North Africa, Asia, and Caribbean. Phase II was completed by the end of May 2011 resulting in seven expert reports.

\section{Main Findings}

One of the breaking findings of our Study was the fact that even though established on cultural and social principles, the $\mathrm{CoE}$ cultural routes became a source of innovation, creativity, small business creation, and cultural tourism products and services development within 25 years of their programme existence. We found that, except for ensuring preservation of European cultural heritage properties and promoting common European values, CoE cultural route networks benefit SMEs by providing markets for SMEs products and contribute to tourism revenue generation in remote destinations.

A number of innovative practices were recorded within the SMEs and various routes during this inquiry, with the organizational, product and service forms of innovation being the most noticeable. Within 25 years of existence, our routes have achieved a notable progress, generated multiple positive impacts on the communities along their destinations, and shown enormous potential for SME generation, competitiveness, cross-border collaboration, networking, and promoting European identity in its unity and its diversity. In addition, the $\mathrm{CoE}$ routes encourage widespread community participation in cultural activities raising awareness of a common cultural heritage.
For example, case study of the Transromanica cultural route conducted by G. Richards (2011) demonstrates that "there are links with SMEs along the route, mainly in the tourism sector. SMEs are also involved in providing services to the route there, mainly in terms of publications, merchandising and design. Many of the contacts are with SMEs involved directly or indirectly with tourism, such as hotels, restaurants and wine producers. ...According to the project leaders in Vale do Sousa, many of the SMEs in the region are aware of the cultural route, even if they may not participate directly. This includes firms in the major economic sectors in the region, like: furniture making and clothing."

Innovations within the cultural routes: A number of interesting initiatives were discovered within cultural route networks that are instrumental in generating tourism SMEs innovation as well as raising visibility for the routes themselves.

Hansa Business Reloaded project, for example, was developed to set up trade markets between SMEs from different Hanseatic cities. The idea was that the cities involved interested local SMEs to the project to explore possibilities for business cooperation and development trans-nationally. Today, his initiative brings together 26 partners in 29 cities from eight different countries in Europe (see Picture 1 for geographic coverage of the project). This creates the critical mass needed for companies to innovate, to raise awareness about the cultural route, and to provide complete and higher value services and products to their customers. Potentially, this will also generate a higher demand for SME-provided tourism services.

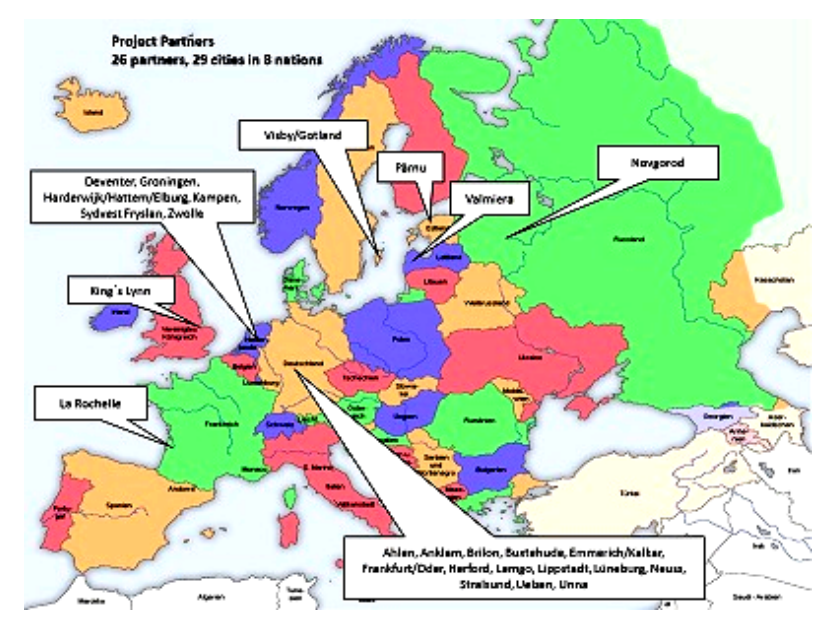

Picture 1. Hansa Route's Business Reloaded Project: geographic coverage

A similar promising initiative in this regard comes from the Transromanica Route that works to establish specific clusters at key locations along cultural routes. This initiative is planned to centre on SMEs, entrepreneurship and tourism. Today, Transromatica offers a selection of tourist packages and trips along the Route in collaboration with local transport companies, hotels, restaurants, wine producers, and tourism offices (Picture 2 below). 


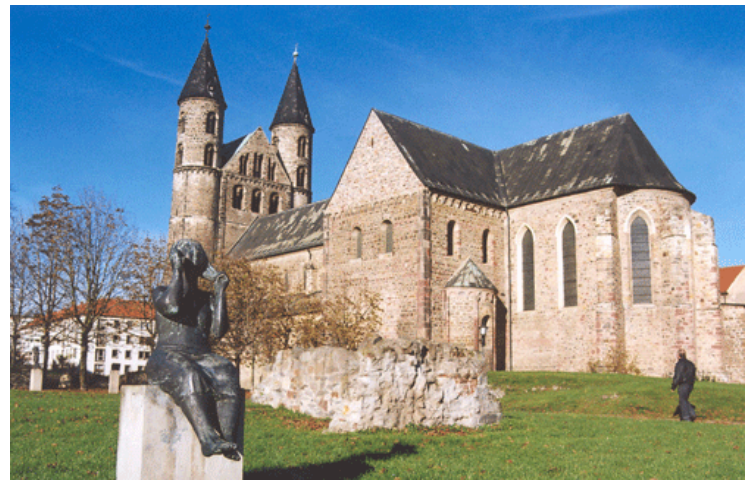

Picture 2. Photo of a church from the Transromanica "Romanesque Route of Saxony-Anhalt by bike" tourism offer

The Via Regia cultural route employs the GIS system to inform its visitors and involved SMEs about provided along the route services. This also allows the SMEs to get broader exposure to interested customers and to interact with them directly, while helping to lower the transaction cost for customers and offering a shorter way for SMEs to the market. For the Via Regia coordinators this additionally implies lower administrative expenditures.

The Olive Tree Route has witnessed the organisation of cultural itineraries on request of Chambers of Commerce from several parts of Greece. A number of SMEs along the Olive Tree Route participate in external trade. These itineraries and missions have provided a good basis for strengthening collaboration between the enterprises and to establish a good foundation for new joint initiatives.

All CoE cultural routes provide unique opportunities for SMEs to develop innovative products and services within the framework of tourism activities that the routes generate. These innovation opportunities can be divided into two types. On the one hand, local SMEs produce products and services with a cultural route label, contributing by this to the promotion of a route. These products and services generally involve adoption of innovative solutions, practices and do not require considerable market and/or territorial horizon expansion (innovation adoption type). On the other hand, some SMEs develop their original products and services based on the unique values and heritage of the cultural route they are involved with (innovative product development). These products and services are innovative, since they are new to local SMEs range of activities and practices (Khovanova, 2010). Table 1 below offers a few examples of innovative practices identified within the $\mathrm{CoE}$ cultural routes.

\begin{tabular}{|c|c|c|}
\hline $\begin{array}{c}\text { Sales } \\
\text { Location }\end{array}$ & $\begin{array}{c}\text { Innovation } \\
\text { adoption }\end{array}$ & $\begin{array}{c}\text { Innovative products } \\
\text { development }\end{array}$ \\
\hline $\begin{array}{l}\text { On-site } \\
\text { sales } \\
\text { fixed-place } \\
\text { consumption }\end{array}$ & $\begin{array}{l}\text { Vin de Saint } \\
\text { Martin, } \\
\text { Phoenician } \\
\text { Route meals, } \\
\text { Ruta de } \\
\text { Juderias stays }\end{array}$ & $\begin{array}{l}\text { Virtual reality shows } \\
\text { (Pyrenean Iron Route), } \\
\text { Pescatourism formulas, } \\
\text { (Archaeological), trekking } \\
\text { and cycling tours, mini- } \\
\text { itineraries, short distance } \\
\text { trajectories as in } \\
\text { Transromanica and } \\
\text { Phoenician Routes, Via }\end{array}$ \\
\hline
\end{tabular}

\begin{tabular}{|c|c|c|}
\hline $\begin{array}{l}\text { On-site } \\
\text { sales } \\
\text { fixed-place } \\
\text { consumption }\end{array}$ & $\begin{array}{l}\text { Vin de Saint } \\
\text { Martin, } \\
\text { Phoenician } \\
\text { Route meals, } \\
\text { Ruta de } \\
\text { Juderias stays }\end{array}$ & $\begin{array}{l}\text { Francigena, Iron Route } \\
\text { Assembling diversified } \\
\text { tourism packages as per } \\
\text { Route des Villes d'eau and } \\
\text { the Pyrenean Iron Route (to } \\
\text { complement the thermal } \\
\text { offer or to blend industrial } \\
\text { patrimony with sculptures, } \\
\text { museum visits**1 and other } \\
\text { forms of art and education) }\end{array}$ \\
\hline $\begin{array}{l}\text { Sales and } \\
\text { consumption } \\
\text { along and } \\
\text { beyond } \\
\text { the cultural } \\
\text { routes' } \\
\text { destinations }\end{array}$ & $\begin{array}{l}\text { Biker tours, } \\
\text { tour operator } \\
\text { formulas on } \\
\text { Transromanica } \\
\text { for China and } \\
\text { US, on Hansa, } \\
\text { the Olive Tree, } \\
\text { Legacy of Al- } \\
\text { Andalus } \\
\text { Routes. } \\
\text { Assembling } \\
\text { existing } \\
\text { hotspots into } \\
\text { packages across } \\
\text { the routes }\end{array}$ & $\begin{array}{l}\text { GPS clocks and flash codes } \\
\text { for ramblers and } \\
\text { monuments, Exhibition, } \\
\text { cycle carrying bus (DNV). } \\
\text { Hansa Business Days, } \\
\text { dedicated IT / web / GIS } \\
\text { applications for use along } \\
\text { the Cultural Routes as per } \\
\text { Via Regia, St Martin of } \\
\text { Tours: long distance } \\
\text { trajectories involving } \\
\text { carriers, brokerage services } \\
\text { and knowledge-intensive } \\
\text { mobility services }\end{array}$ \\
\hline
\end{tabular}

Table 1. Types of innovations within the cultural routes and their SMEs

Overall, the Study shown that development of cultural tourism is a logical next step in developing $\mathrm{CoE}$ cultural routes since this type of tourism builds on the uniqueness of remote destinations, local knowledge, skills, heritage and traditions. $\mathrm{CoE}$ cultural routes have significant potential for cultural tourism development as well as for the promotion of economic, social and territorial cohesion in Europe. A number of cultural route partners are collaborating effectively and are producing remarkable results, particularly, at the local level. Our experts concluded that these collaborative practices could be enhanced by professionally applied network governance models and availability of funding for key skills development, capacitybuilding, training, networking, and cross-marketing activities.

Elements of sustainable tourism management: It is important to note that the $\mathrm{CoE}$ cultural routes differ not only in their thematic focus but also in their network structures, management capacities, development approaches, geographical dimensions, target groups, and quality standards of the products and services. Undoubtedly, this diversity contributes to a variety of cultural projects, products and services creation along cultural routes destinations. At the same time, these differences generate a need to adapt or develop specially-designed management tools and models that could be applied to individual routes and would reflect the uniqueness of every itinerary, while

** In case of the Pyrenean Iron Route, it can be argued that the elaboration of the Route led to a revitalization of several pedagogical centers into the Route-based cultural tourism chain. E.g. the museum of Ripoll (Catalonia, Spain) to which didactic visits are organized, and a former school for metal working in the Basque Country (Spain) where interactive scenographies in relation to metallurgy are presented. These are clear examples of how the Cultural Routes valorize European cultural values and heritage. 
accounting for diversity of their characteristics. The Study experts concluded that such a need could be best addressed by incorporating elements of sustainable and respectful tourism to cultural routes heritage management and performance evaluation.

Sustainable development is a process that "ensures to meet the needs of the present without compromising the ability of future generations to meet their own needs", according to the Brundtland Report (1993), officially entitled as "Our Common Future" and first published by the World Commission on Environment and Development (WCED) in 1987. This definition of sustainable development implies the limits imposed by the present state of technology and social organization on the environmental resources. It also speaks to the limited capacity of the biosphere to absorb the effects of human activities.

Therefore, sustainable development is not a fixed state of harmony but rather a process of change with the major objective to satisfy human needs and aspirations while protecting natural environment and creating structures that ensure economic development of the society. The five basic principles of sustainable development, according to the Brundtland Report, are:

- Holistic planning and strategy

- Preserving essential ecological processes

- Protection of human heritage and biodiversity

- Intergenerational equity

- Balanced fairness and opportunities between nations

The CoE cultural routes have already moved a step further since the time the Study (2011) conclusions and recommendations were made available. Today, our cultural route managers are working along the lines of five basic principles of sustainable development improving their models of cultural heritage management, performance evaluation, and applying these principles to their individual contexts. This was made possible by a new joint project on European Cultural Routes cofounded by the Council of Europe and the European Commission, who put the financial and human resources together to advance the quality of cultural heritage management in Europe.

These new cultural heritage management models are also in line with the guidelines of the UNWTO (2003) sustainable tourism development and management practices. They focus on optimal use of environmental resources, maintaining essential ecological processes and helping to conserve natural heritage and biodiversity, respect the socio-cultural authenticity of local communities, contribute to inter-cultural understanding. They also ensure long-term economic operations while providing socio-economic benefits to all participants.

Along these lines, the Study also recommended the CoE cultural routes to maximise their potential in terms of digitalization, new social media and web use. These tools were suggested to be used in the form of integrated umbrella platform. The majority of the routes already established dynamic and interactive websites providing regular updates on their activities, offering interactive maps, events lists and best practice exchange (see Picture 3 for an example of interactive map). In this way the routes could seize the opportunity to develop new cultural tourism product and service offers, and to get a broader exposure to potential customers.

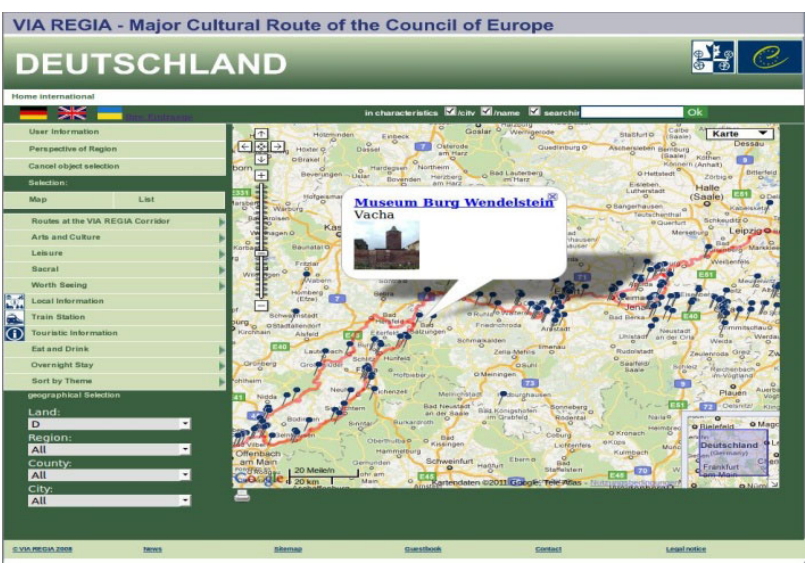

Picture 3. A screenshot of an interactive map on the website of the Via Regia Cultural Route of Council of Europe

The Study (2011) revealed a range of challenges to the CoE cultural routes environments that require further attention. These include:

- enhancing trans-national connectivity of the cultural route networks,

development of a stronger brand image and marketing strategies,

design/implementation of quality and sustainable tourism standards, adjusted to cultural routes environments,

enhancing human and financial resources of the routes, and

development of relevant (network and performance) evaluation tools.

The Study concluded that in order to address these challenges, and to assure that the potential of the CoE cultural routes for sustainable and inclusive growth, for responsible cultural tourism development, for promotion of cultural heritage preservation, and for economic, social and territorial cohesion in Europe is fully realized, it is important to develop a strategy for the $\mathrm{CoE}$ cultural routes that would include the following elements:

better articulation of the added-value of the cultural tourism sector in general, related SMEs and their networks for economic and social development of cultural routes' destinations,

strengthening the capacity of the cultural routes to engage effectively in local and regional development and encourage a greater professionalism in the area of cultural routes network governance,

development of relevant cultural routes improvement strategies - at local, regional and transnational levels built on partnerships between public authorities, cultural organizations, corporate business, SMEs, and civil society representatives,

improved communication between and within cultural route networks especially at regional and transnational levels: successful experiences should be further exploited and disseminated, identification and exchange of examples of best practice and innovations between and within cultural route networks, 
- development of better evaluation techniques and methodologies and their more extensive application to the Cultural Routes and their coordinating bodies, and

addressing the issue of quality and sustainable tourism criteria development for the cultural routes

\section{CONCLUSIONS}

This paper offered an overview of the Study on the Impact of the CoE Cultural Routes on SMEs Innovation, Competitiveness, and Clustering (Khovanova-Rubicondo et al. 2011) that demonstrated how the need for implementing the sustainable tourism management practices is growing within the $\mathrm{CoE}$ cultural routes, and what mechanisms are to be put in place in order to fully incorporate these practices.

One of the breaking findings of the Study is that, even though founded on social and cultural principles with no particular goal to create economic benefits or raise any income, CoE cultural routes today serve as a source of innovation, small business creation, and cultural tourism products and services development.

The author of this paper is convinced that the below provided conclusions can assist cultural heritage managers and policy makers around the globe in their better understanding of socioeconomic and tourism potential of world cultural heritage sites, while encouraging respectful and sustainable heritage management approaches.

Cultural route constitutes a new category of cultural good which generates an interaction between a monument in need of protection and development, and the cultural or regional context to which it must be linked in order to be fully understood and appreciated.The promotion of responsible and sustainable tourism is a logical next step in developing cultural routes in Europe and globally, since this type of tourism builds on the uniqueness of cultural destinations, local knowledge, skills, heritage and traditions.

It is also important to notice that cultural projects - such as cultural routes - are capable of not only improving economic conditions of remote destinations through income generation for local communities, but also of contributing directly to local communities' competitiveness, new employment creation, and social well-being of their citizens. Increasingly, the cultural routes also become a focal point for trans-national networking and cluster development.

Sustainable development and maintenance, respectful treatment of the environment and cultural heritage sites are crucial for successful functioning of CoE-certified and cultural itineraries/ projects and their involved SMEs around the world. Cultural routes offer an impressive mix of different products and services to their customers. They attract larger and larger number of visitors increasing by this the demand for their cultural goods and necessitating the need for related services. Yet, it is important to keep in mind that this demand for cultural goods should not overthrow the supply in a sense that physical and environmental capacities of the heritage sites would be jeopardized.

Therefore, cultural heritage should be managed in a wellbalanced way to provide for continuous protection and proper maintenance of cultural heritage sites while offering access to larger audiences of visitors who come to appreciate their uniqueness.

Finally, a rapid growth in cultural and tourism destinations worldwide means that the CoE-certified cultural routes and similar projects today face the challenge to be even more competitive and quality conscious in order to attract more tourists in a global marketplace. This reconfirms the need for implementation of quality and sustainable tourism development standards along the cultural routes destinations, as well as the necessity to develop a new coherent roadmap for cooperation between similar initiatives globally.

\section{References}

Bramwell, B. and B. Lane. Sustainable tourism: an evolving global approach. Journal of Sustainable Tourism. 1(1). 1993.

Khovanova-Rubicondo, K. (et al.), 2011. "Study on the Impact of the European Cultural Routes on SMEs Innovation, Competitiveness, and Clustering," Council of Europe, Strasbourg, France.

http://www.coe.int/t/dg4/cultureheritage/culture/routes/StudyC $\underline{\mathrm{R} \text { en.pdf }}$ (accessed 8 June 2011)

Khovanova, K., 2010. How fiscal health of a government affects its innovation. UMI Publishing.

Richards, G. in Khovanova-Rubicondo, K. (et al.), 2011. "Study on the Impact of the European Cultural Routes on SMEs Innovation, Competitiveness, and Clustering," Council of Europe, Strasbourg, France.

UNWTO, 2003. "Recommendations to governments for supporting and/or establishing national certification systems for sustainable tourism. Madrid, Spain.

http://sdt.unwto.org/sites/all/files/docpdf/certification-govrecomm.pdf (accessed 8 June 2011)

\section{Acknowledgements}

The Study on the Impact of the CoE Cultural Routes on SMEs Innovation, Competitiveness, and Clustering was jointly funded by the European Commission (EC, DG Tourism and Industry) and the Council of Europe, and implemented by the Council of Europe (CoE). Coordinators: Mr. V. Izzo (EC), Dr. K. Khovanova-Rubicondo (CoE), kseniya.khovanova@gmail.com

A special thank you to the experts who contributed to this Study: S. Bagwell, D. Dodd, N. Hall, B. Kamp, U. Marx, G. Richards, and J. Tresseras. 